\title{
Administration of insulin-like growth factor-I (IGF-I) peptides for three days stimulates proliferation of the small intestinal epithelium in
} rats

\author{
C B Steeb, J F Trahair, L C Read
}

\begin{abstract}
It has previously been shown that longterm administration of insulin-like growth factor-I (IGF-I) or the analogue Long $R^{3}$ IGF-I (LR ${ }^{3}$ IGF-I) selectively stimulate growth of the gastrointestinal tract in gut resected, dexamethasone treated, and normal rats. In this study, the short-term effects of IGF-I administration on intestinal proliferation have been investigated. Female rats (110 g, five-six/group) were infused for three days with $2 \cdot 5$ $\mathrm{mg} / \mathrm{kg} /$ day of either IGF-I or LR ${ }^{3}$ IGF-I and compared with vehicle treated or untreated control rats. LR ${ }^{3}$ IGF-I but not IGF-I increased body weight and wet tissue weight of the small and large intestine $(+20 \%)$, compared with controls. Tissue weight responses were independent of food intake and were reflected in the histology of the tissue. In LR ${ }^{3}$ IGF-I treated animals, duodenal and ileal crypts length were increased by 13 and $22 \%$, respectively, associated with an increase in crypt cell number. No such histological changes were seen in IGF-I treated rats. Tritiated thymidine labelling indices were significantly increased after administration of either IGF-I or LR $^{3}$ IGF-I (up to $14 \%$ ) in both the duodenum and ileum. In IGF-I treated rats, increased nuclear labelling was not associated with an increase in the crypt compartment. In contrast, $L^{3}{ }^{3}$ IGF-I induced proportional increments in thymidine labelling and crypt size, suggesting that LR $^{3}$ IGF-I is not only more potent than the native peptide but also induced proliferative events more rapidly. In the colon, the thymidine labelling index was low, however, a non-significant increase in the number of cells labelled with thymidine was seen. These results suggest that within a three day treatment period intestinal mitogenesis is more advanced in animals treated with $\mathbf{L R}^{3}$ IGFI. The differences in proliferative response between the two peptides may be accounted for by variations in pharmacokinetics, clearance rates, and interactions with circulating and tissue specific binding proteins.
\end{abstract}

(Gut 1995; 37: 630-638)

Keywords: insulin-like growth factor, epithelium, proliferation, thymidine labelling index, crypt growth fraction.
Insulin-like growth factors (IGF-I and IGF-II) are multifunctional polypeptides that possess the ability to exert insulin-like metabolic activity and regulate cell proliferation and differentiation in a variety of cell types and tissues. IGF-I mediates growth hormone dependent growth and stimulates somatic growth and that of visceral organs including the kidneys, thymus, adrenals, and the spleen. In the circulation, IGFs are bound to specific IGF binding proteins, which function as modulators of IGF action. They interact with their target tissues by membrane bound receptors to act in an autocrine, paracrine or endocrine manner, or all three. ${ }^{1}$ IGFs are ubiquitously distributed and have been detected in tissue extracts as well as body fluids. IGF-I immunoreactivity has been shown in the human fetal stomach ${ }^{2}$ and in fetal rat intestine. ${ }^{3}$ In neonatal pigs, growth and maturation of the intestinal mucosa coincides with an increase in IGF-I immunoreactivity. ${ }^{4}$ Furthermore, IGF-I immunoreactivity has also been shown in saliva, gastric, pancreatic, and extrapancreatic excretions and in jejunal chyme. $^{5}$

Several studies in animal models of gastrointestinal adaptation have shown that administration of IGF-I peptides selectively stimulate growth of the gastrointestinal mucosa. ${ }^{6-8}$ More recently, we have shown that IGF-I peptides also play an important part in gastrointestinal growth and function in normal adult rats. ${ }^{9}$ In that study we gave increasing doses of IGF-I or LR $^{3}$ IGF-I, a potent analogue with an $\mathrm{N}$-terminal extension showing reduced binding affinity to IGF-binding proteins as well as the type 1 receptor, ${ }^{10}$ for 14 days to normal, female rats. After the 14 days of treatment with either IGF-I or LR $^{3}$ IGF-I, body weight gain and gastrointestinal weights were significantly increased. The LR ${ }^{3}$ IGF-I was severalfold more potent than the native IGF-I in all responses. Furthermore, wet tissue weights were increased in a dose dependent manner and the proximal small intestine was identified as the most responsive region. Detailed histological analyses showed that IGF-I peptide administration stimulated the growth of the proliferative compartment (crypt) and the functional compartment (villi), so that at the end of the 14 day treatment period crypt depth and villus height were increased by up to $30 \%$ above control values. More importantly, however, IGF-I peptide administration induced a proportional increase in potentially proliferative 
enterocytes as shown by immunohistochemical detection of cells positive for proliferative cell nuclear antigen (PCNA). The proportionality between the proliferative and maturation compartment of the crypt as well as between crypts and the villi was maintained. ${ }^{9}$ These findings have led to the conclusion that administration of either IGF-I or LR ${ }^{3}$ IGF-I peptide for a prolonged period stimulate mucosal growth, resulting in a new steady state between cell loss and cell production.

This study was undertaken to identify the early proliferative responses of the intestinal epithelium that led to this new steady state after IGF-I or LR ${ }^{3}$ IGF-I administration. IGFI and LR ${ }^{3}$ IGF-I were compared to determine if the two peptides differed in their potency to evoke proliferative responses of the intestinal epithelium during this early period. Furthermore, we investigated if the proliferative responses were similar in different regions of the intestine. In review of the results from the aforementioned study, a short-term infusion protocol was used. The age and body weights of the rats as well as the peptide dose and infusion protocol have been replicated so that direct comparisons could be made between the two studies.

\section{Methods}

RECOMBINANT IGF-I PEPTIDES

Recombinant human IGF-I and the recombinant analogue LR $^{3}$ IGF-I was provided by GroPep, Adelaide, South Australia. The IGF-I analogue LR $^{3}$ IGF-I, has an arginine replacing glutamate at position 3 and an $\mathrm{N}$-terminal extension comprising the amino acids MetPhe-Pro-Ala-Met-Pro-Leu-Ser-Ser-Leu-PheVal-Asn.

\section{EXPERIMENTAL DESIGN}

\section{Animals}

Female, hooded Wistar rats of approximately $100 \mathrm{~g}$ were obtained from the CSIRO, Division of Human Nutrition breeding colony. All animals were housed individually in Techniplast metabolism cages and maintained at $25^{\circ} \mathrm{C}$ with a 12 hour light/dark cycle. They were fed a powdered diet containing $180 \mathrm{~g}$ casein and $2.5 \mathrm{~g}$ methionine $/ \mathrm{kg}$ body weight as the nitrogen source. Water and food were available ad libitum. The experimental protocol was approved by the Animal Care and Ethics Committee of the Women's and Children's Hospital and followed the Australian Code of Practice for the Care and Use of Animals for Scientific Purposes.

\section{Experimental protocol}

IGF-I peptides were infused subcutaneously for a three day period. All animals were acclimatised to the metabolism cages for a three day period, followed by a four day pretreatment period. During the pretreatment period and the three days of peptide infusion, daily measurements of body weight, food, and fluid intake as well as urinary and faecal output were taken at precisely 24 hour intervals. Between 0900 and 1200 hours on the morning after the pretreatment period, the rats were anaesthetised with $0.04 \mathrm{ml} / \mathrm{kg}$ Brietal for osmotic mini-pump (Alzet, Model 1003D, Alza, Palo, CA, USA) implantation within the subcutaneous scapular region. The pumps were filled with either IGF-I or LR ${ }^{3}$ IGF-I or contained the vehicle alone $(0.1 \mathrm{M}$ acetic acid). Each rat received $2.5 \mathrm{mg} / \mathrm{kg} /$ day of either IGF-I or LR ${ }^{3}$ IGF-I, thus at a mean pumping rate of $0.99 \mu \mathrm{l} / \mathrm{h}$, each rat received $278 \mu \mathrm{g} /$ day for a three day period. There were six rats in each of the vehicle, IGF-I, and LR ${ }^{3}$ IGF-I treated groups and a control group $(n=5)$, receiving no treatment or pump was also included. The study was divided into two animal trials. The first trial contained three rats from each of the two peptide treatment groups, three vehicle treated rats, and three untreated control animals. The second trial contained three rats from each of the peptide treated and vehicle treated groups and two untreated control animals. The trials were staggered by one day. The pumps were not primed before implantation, so that in accordance with the manufacturer's instructions, the full pumping rate would be reached approximately four hours after insertion of the pumps between 1300-1600 hours. No special postoperative care of the animals was required.

During the three days of peptide infusion, daily measurements of body weights and metabolic collections were continued. At the end of the three day treatment period between 1300 and 1600 hours, each animal was injected with a single intraperitoneal injection of $0.5 \mu \mathrm{Ci} / \mathrm{g}$ body weight of tritiated thymidine (Amersham International, Buckinghamshire, England, specific activity $25 \mathrm{Ci} / \mathrm{mol}$ ) in the same order as pump implantation. Exactly one hour after the injection of the isotope, the animal was stunned and decapitated, thus all rats received IGF-I peptides for the same length of time. The abdomen was opened by a midline incision and the entire gastrointestinal tract was rapidly excised and placed onto an ice cold glass slab. The stomach, small and large intestine and the caecum were isolated. The duodenum was separated from the small intestine at the ligament of Treitz and its empty weight and length was recorded. The weight of the remaining small intestine, large intestine, and the caecum were taken after removal of gut contents. All length measurements of intestinal segments were made by placing the tissue horizontally onto a cold glass slab, avoiding the stretching of the tissue. For histological analyses, multiple tissue sections were collected from the proximal duodenum (starting $1 \mathrm{~cm}$ caudal to the pyloric sphincter) and the distal ileum, while large intestinal samples were collected from the proximal colon. The segments were rinsed in cold $0.9 \% \mathrm{w} / \mathrm{v} \mathrm{NaCl}$ and immediately fixed in Bouin's fluid. Total gut weights and length were calculated as the sum of all intestinal components. 
Histology and autoradiography

For quantitative histological morphometry, tissue segments of the duodenum, ileum, and colon were fixed in Bouin's fluid for four hours and stored in $70 \%$ ethanol before processing for routine paraffin wax embedding. From each of the intestinal regions sampled, four to six tissue segments were embedded in transverse orientation in the same mould and six serially cut sections of $2 \mu \mathrm{m}$ thickness were prepared for each animal. The first of the serially cut sections from each animal was dewaxed, re-hydrated, stained with haematoxylin and eosin, and mounted with DePex (Gurr, BDH Chemicals, Kilsyth, Australia) for histological analyses. The remaining five serially cut sections were used for autoradiography. For this purpose, they were de-waxed, re-hydrated, and briefly dipped in $10 \%$ lithium carbonate to reduce chemography during autoradiographic processing. The sections were then incubated at room temperature for 30 seconds in autoradiographic emulsion (LM-1, Amersham, Australia) at a dilution of $1: 1$ with distilled water. After incubation, the slides were chilled on a pre-cooled tray for 10 minutes and air dried for two to three hours in the dark room. All slides were stored at $4^{\circ} \mathrm{C}$ in light tight photographic slide containers and kept for 2-20 days. After exposure, the slides were developed in Ilford Phenisol Developer (Amersham, Australia) at room temperature (dilution 1:4) for six minutes and rinsed in sodium thiosulphate (BDH Chemicals, Australia) for four minutes. The developed slides were rinsed for 15 minutes in de-ionised water, counterstained with haematoxylin, and mounted with DePex. Negative control slides were included from animals not injected with the isotope. In addition, a single, $2 \mathrm{~cm}$ long tissue segment from each region was embedded facing serosal side down, so that tissue sections orientated longitudinal to the bowel lumen could be obtained. From serially cut sections, tissue segments representing the crypt:villus junction were identified and utilised to count the number of enterocytes located around the circumference of the crypt (crypt row count).

\section{Analyses}

Histological sections were examined with an Olympus BH-2 light microscope. Quantitative morphometric analysis was conducted using a drawing tube attached to the microscope and measurements were taken using a digitising tablet (Summa Sketch II, Summa graphics), coupled to an Apple Macintosh IIci computer. In the duodenum and ileum, crypt depth was measured in 15 well oriented crypts. The depth of the colonic crypts was measured in 15 crypts randomly selected, with care taken to avoid sections containing Peyer's patches.

The dose of tritiated thymidine used in this study produced clear labelling of S-phase nuclei, showing numerous black grains deposited over the nuclei and a negligible background. A minimum of six grains per nuclei was used to define positively labelled cells. Preliminary analyses determined that the slides had to be exposed for at least 10 days to obtain adequate signal of the isotope. Accordingly, all analyses were carried out on sections exposed for 10 days. Proliferative parameters were assessed in 30 crypts from each animal in the duodenum, ileum, and colon. Analyses were confined to crypts where the entire length could be completely visualised and which contained a single layer of epithelial cells only. In each crypt, a single column (right hand column) along the longitudinal axis of the crypt was assessed and the total number of cells and the number and position of tritiated thymidine labelled cells was recorded. For each of the intestinal regions, the labelling index was calculated as the ratio of labelled cells to total cell number for each crypt column. In addition, the circumferential cell count (crypt row count), measured as the number of epithelial cells around the circumference at the crypt:villus junction was measured in the duodenum and ileum in serial cut sections from tangentially embedded material. The product of the crypt column count and the crypt row count was used to estimate the total crypt cell population in all small intestinal regions.

For each animal, thymidine labelling index distribution profiles were established for the duodenum and the ileum. From these curves, the cell position within the crypt at which maximal thymidine labelling occurs and the cell position of half maximum thymidine labelling was identified. The maturation compartment of the crypt in which epithelial cells have lost their proliferate capabilities and acquire their mature, functional properties was identified from these curves as the region above the last labelled cells within the crypt. To determine if IGF-I peptides increase thymidine incorporation into enterocytes in the lower and mid-crypt region, the cumulative number of cells labelled with tritiated thymidine up to cell position 19 was calculated. The crypt growth fraction, which identifies the proportion of proliferating cells within the crypt, was calculated for each animal from the thymidine labelling distribution profiles of 30 perfectly orientated crypts by dividing the cell position at which half maximum labelling occurred by the total number of cells per cell column.

\section{Statistical analyses}

All values in Tables and Figures are expressed as means (SEM). All groups were compared by a one way analysis of variance (ANOVA) and where significance was achieved $(p<0.05)$ a post-hoc Dunnett's test (SuperANOVA, Abacus Concepts, Berkeley, CA) was applied to identify variations between treatment groups and either vehicle treated or control animals. To examine the degree to which body weight gain and fluid balance vary after IGF peptide treatment, data were analysed by product-moment correlations and significance was tested with a $t$ test with n-2 degrees of freedom. ${ }^{11}$ 
TABLE I Body weight ( $g$ ), and body weight gain ( $g / 3$ days) and average food consumption (g/24 hours) in rats treated for three days with $2 \cdot 5 \mathrm{mg} / \mathrm{kg} /$ day of either IGF-I or LR ${ }^{3} I G F-I$ compared with vehicle treated or untreated control rats

\begin{tabular}{lllll}
\hline $\begin{array}{l}\text { Treatment } \\
\text { group }\end{array}$ & $\begin{array}{l}\text { Body weight } \\
\text { starting }(g)\end{array}$ & Final $(g)$ & $\begin{array}{l}\text { Gain } \\
(g / 3 \text { days) }\end{array}$ & $\begin{array}{l}\text { Average food } \\
\text { intake }(g / 24 \text { hours) }\end{array}$ \\
\hline Control (n=5) & $110 \cdot 5(2 \cdot 1)$ & $122 \cdot 3(2 \cdot 0)$ & $11 \cdot 8(1 \cdot 4)$ & $13 \cdot 7(0 \cdot 5)$ \\
Vehicle (n=6) & $111 \cdot 2(2 \cdot 6)$ & $127 \cdot 0(2 \cdot 8)$ & $15 \cdot 4(1 \cdot 9)$ & $13 \cdot 6(0 \cdot 3)$ \\
IGF-I (n=6) & $108 \cdot 6(2 \cdot 6)$ & $122 \cdot 1(2 \cdot 7)$ & $13 \cdot 5(2 \cdot 1)$ & $13 \cdot 4(0 \cdot 4)$ \\
LR $^{3}$ IGF-I (n=6) & $109 \cdot 7(0 \cdot 6)$ & $134 \cdot 9(1 \cdot 3)^{\star} \dagger$ & $25 \cdot 2(1 \cdot 4)^{\star} \dagger$ & $12 \cdot 9(0 \cdot 1)$ \\
\hline
\end{tabular}

All values are expressed as means (SEM). Statistical significance from the vehicle treated group is indicated by ${ }^{*}: p<0.01$ and from the untreated control group by $t: p<0.01$, ANOVA, Dunnett's post-hoc test (two tailed).

\section{Results}

The body weight at the start of the study averaged $97.9(1.0) \mathrm{g}(\mathrm{n}=23)$ for all rats. After four days of acclimatisation to the metabolism cages the average body weight increased to $109.9(1 \cdot 0) \mathrm{g}$. Rats were then randomised into treatment groups such that no statistically significant differences in body weight were apparent between treatment groups (Table I). Infusion of $2.5 \mathrm{mg} / \mathrm{kg} /$ day of LR $^{3} I G F-I$ for a three day period resulted in a significantly higher body weight $(134.9(1 \cdot 1) \mathrm{g})$ compared with animals treated with vehicle $(127 \cdot 0(2 \cdot 8)$ g) or normal rats (control group, $122 \cdot 3(2 \cdot 0) \mathrm{g}$ ) without an implanted mini-pump (Table I). The body weight gain in $\mathrm{LR}^{3} \mathrm{IGF}-\mathrm{I}$ treated animals could not be attributed to an increase in food intake, as food consumption was approximately $13 \mathrm{~g} /$ day for all groups (Table I). Accordingly, food conversion efficiency, calculated as the ratio of average daily body

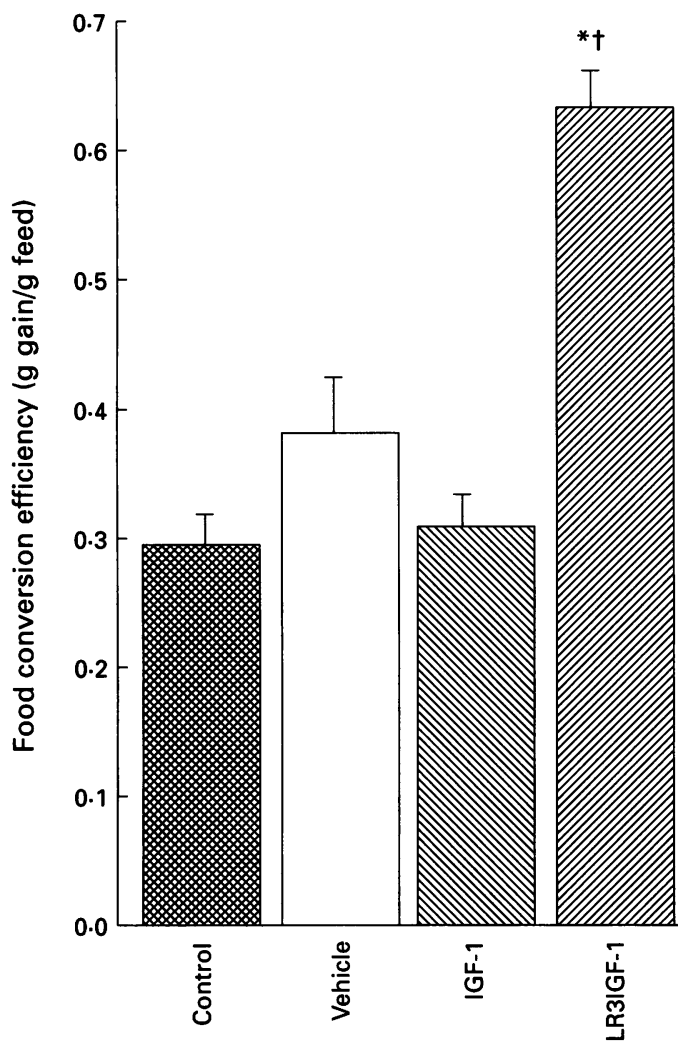

Figure 1: Food conversion efficiency ( $g$ body weight gain/g feed) in normal adult rats treated for three days with $2 \cdot 5$ mg/kg/day of IGF-I or $L R^{3} I G F-I$ compared with either vehicle or untreated control rats. Values are means (SEM) for 6 rats/group ( $n=5$, control group). Statistical significance from vehicle treated rats is indicated by ${ }^{\star}: p<0.0001$ and by $t: p<0.0001$ (untreated control group) as detected by $A N O V A$ weight gain to food consumption for the three day treatment period was highly significant in the $\mathrm{LR}^{3} \mathrm{IGF}-\mathrm{I}$ treated group $(\mathrm{p}<0.0001)$ when compared with either vehicle, control or IGF-I treated animals (Fig 1). To determine if the accelerated weight gain in the LR $^{3}$ IGF-I treated animals could be attributed to fluid retention, the fluid balance (fluid intake/24 hours minus fluid output/24 hours) was estimated for all animals. Although fluid intake was highly variable throughout the three day treatment period in all groups, no statistically significant difference was detected in either fluid intake or urinary output over the experimental period, arguing against fluid retention as a possible mechanism for the extra weight gain seen in $\mathrm{LR}^{3} \mathrm{IGF}-\mathrm{I}$ treated rats (results not shown). To examine the degree to which body weight gain and the fluid balance correlate after IGF-I peptide treatment, productmoment correlation coefficients were calculated for the combined data. No statistical significant correlation was found between body weight gain and the fluid balance during the three day treatment period in either treated or untreated rats $\left(r_{\text {obtained }}=0.27, r_{\text {critical }}=0.42\right.$ at $\mathrm{p}<0.05$ )

Gastrointestinal weight in the animals fitted with the vehicle pump was similar to the gut weight of untreated control rats, showing that implantation of the pumps had no effect on gastrointestinal tissue growth. Comparison between the vehicle group and the animals treated with $2.5 \mathrm{mg} / \mathrm{kg} /$ day of LR $^{3} I G F-I$ showed, however, that the increased body weight gain in the $\mathrm{LR}^{3} \mathrm{IGF}-\mathrm{I}$ group was reflected in the wet tissue weights of their gastrointestinal tissues. Total gut weight, small and large intestinal weight were increased by $19 \%, 22 \%$, and $21 \%$ respectively compared with vehicle treated animals (Fig 2 (A), (C), and (D)), while stomach weight increased by $12 \%$ after treatment with LR $^{3}$ IGF-I (Fig 2 (E)). Selective action of $\mathrm{LR}^{3} \mathrm{IGF}-\mathrm{I}$ on the intestinal tissues was evident when corrections for body weight gain were made, so that fractional gut weight (total gut weight/kg body weight) was significantly increased in $\mathrm{LR}^{3} \mathrm{IGF}$ I treated animals $(56.6(1.4), \mathrm{p}<0.01)$ compared with either IGF-I $(48 \cdot 5(1 \cdot 3))$ or vehicle treated control animals $(50 \cdot 3(1 \cdot 1))$, Fig $2(B)$. The increase in gastrointestinal tissue weight in LR ${ }^{3}$ IGF-I treated animals contrasts considerably with the results obtained for IGF-I treated animals, so that infusion of $2.5 \mathrm{mg} / \mathrm{kg} /$ day of recombinant IGF-I did not affect body weight gain or gastrointestinal tissue weights (Table I and Fig 2 (A-E)). Increases in intestinal length were not seen in any of the animals treated for three days with the IGF-I peptides (results not shown).

We have previously shown that longterm administration of $2.5 \mathrm{mg} / \mathrm{kg} /$ day of IGF-I peptides to normal female rats selectively stimulated the growth of intestinal mucosa, so the main focus here was to assess the mitogenicity of IGF peptides during the initial period of peptide administration. In this study, administration of $\mathrm{LR}^{3} \mathrm{IGF}-\mathrm{I}$ for only three days resulted in a statistically significant increase 

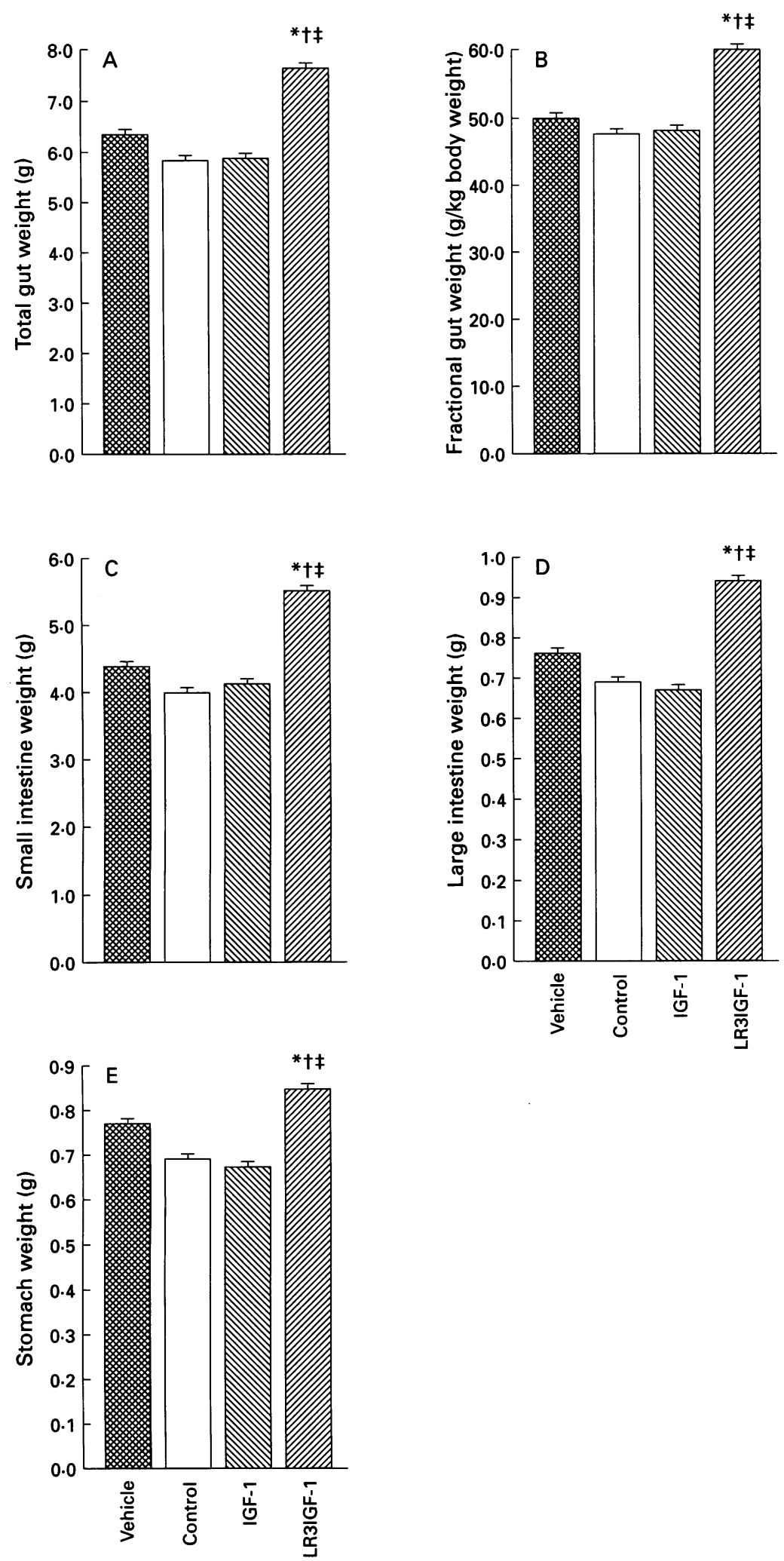

Figure 2: Total gut weight $(A)$, fractional gut weight $(B)$, small intestinal weight $(C)$, large intestinal weight $(D)$, and stomach weight $(E)$ in normal female rats treated for three days with either $2.5 \mathrm{mg} / \mathrm{kg} /$ day of insulin-like growth factor-I peptides compared with vehicle or untreated control rats. All values are means (SEM) with 6 rats/groups ( $n=5$, control group). Significance from the vehicle group is indicated by $*: p<0.01$ and from control group). Significance from the vehicle group is indicated by ${ }^{3}: p<0 \cdot 01$ and from
control groups by $t: p<0.01$. A significant difference between $L R^{3} I G F-I$ and the same dose of IGF-I is indicated by $\ddagger: p<0 \cdot 01$, as detected by ANOVA, Dunnett's (two tailed).

$(\mathrm{p}<0.01)$ in crypt depth, both in the duodenum $(+8 \%)$ and in the ileum $(+13 \%)$, compared with vehicle treated animals (Table II). The increased crypt depth in this group was associated with a proportional increase in the number of cells per crypt column (Table II). Furthermore, the circumferential cell count (crypt row count) was also significantly increased in both small intestinal segments, resulting in an overall increase in crypt cell population by approximately $30 \%$ (Table II). Administration of LR $^{3}$ IGF-I also stimulated proliferation of the colonic mucosa within the three day infusion period. Colonic crypt depth in $\mathrm{LR}^{3} \mathrm{IGF}-\mathrm{I}$ treated animals was marginally increased in comparison with vehicle treated animals but not control treated animals; as in the small intestine, colonic crypt hyperplasia was accompanied by a statistically significant increase in the crypt cell column count (Table II).

To further assess the mitogenic properties of the IGF-I peptides on the intestinal epithelium, we constructed thymidine labelling distribution profiles of the duodenum and ileum for each animal. In the duodenum of control or vehicle treated animals a total of $29-30 \%$ of the crypt cells were labelled with the isotope (crypt labelling index), Table III. In both groups, the thymidine labelling indices were low in the basal cell positions (cell position 1-4). From cell position 5-16, however, labelling indices increased, reaching a maximal labelling of approximately $60 \%$ for control and vehicle treated animals (Table III and Fig 3 (A) and (B)). After cell position 16, proliferative indices declined to reach half maximum labelling at cell position 20 and from cell position 29-35 in the crypt column, no labelled cells were apparent (Fig 3 (A) and (B)). Thus the maturation compartment of the crypt was identified from cell position 29 upwards. The crypt growth fraction for the vehicle and untreated control rats was calculated at approximately $60 \%$.

In the duodenum of the LR ${ }^{3}$ IGF-I treated animals, the crypt cell labelling index was significantly increased $(32.7 \%)$ compared with the control groups (29-30\%), Table III. As for the control and vehicle groups, low proliferative indices were evident in the first few cell positions, however, increased crypt cell labelling was reflected in an increased maximum labelling, calculated at $66 \%$, at cell positions 5-16 (Table III and Fig 3 (D)). Furthermore, the number of thymidine labelled cells up to cell position 19 was also significantly greater in LR $^{3}$ IGF-I treated rats compared with either vehicle or untreated control rats (Table III). After cell position 16, the per cent thymidine labelling declined more slowly than in the vehicle or control group, so that half maximum labelling was not reached until cell position 24 . Thymidine labelling was detectable up to cell position 36 in this group, showing that the maturation compartment (cell position 36-42) was shifted upwards, in proportion with the increase in the crypts compartment. This shows that LR $^{3} I G F-I$ administration for three days led to a significant increase in the number of crypt cells, associated with an increase in the proportion of cells labelled, in particular in the lower and mid-crypt region (up to cell position 19) and an increase in maximal labelling. Most importantly, however, LR $^{3}$ IGF-I also increased the cell position of half maximum labelling in 
TABLE II Histological parameters in the duodenum, ileum, and colon of female rats treated for three days with or without $2 \cdot 5 \mathrm{mg} / \mathrm{kg} /$ day of $I G F-I$ or $L R^{3} I G F-I$

\begin{tabular}{|c|c|c|c|c|}
\hline \multirow[b]{2}{*}{ Histological parameter } & \multicolumn{4}{|c|}{ Treatment group } \\
\hline & Control & Vehicle & $I G F-I$ & $L R^{3} I G F-I$ \\
\hline \multicolumn{5}{|l|}{ Duodenum } \\
\hline Crypt depth $(\mu \mathrm{m})$ & $260(7)$ & $255(5)$ & $257(5)$ & $293(14)^{\star} \ddagger$ \\
\hline Crypt column count (no of cells) & $34 \cdot 1(1 \cdot 1)$ & $35 \cdot 1(0 \cdot 2)$ & $33 \cdot 7(0.5)$ & $41.7(0.9)+5$ \\
\hline Crypt row count (no of cells) & $19 \cdot 3(0 \cdot 3)$ & $20 \cdot 0(0 \cdot 3)$ & $19 \cdot 8(0 \cdot 3)$ & $21.8(0.5)+5$ \\
\hline Crypt population (no of cells) & $656(14)$ & $702(13)$ & $668(9)$ & $910(22)+5$ \\
\hline \multicolumn{5}{|l|}{ Ileum } \\
\hline Crypt depth $(\mu \mathrm{m})$ & $190(8)$ & $203(7)$ & $192(5)$ & $231(4)+5$ \\
\hline Crypt column count (no of cells) & $29 \cdot 4(0 \cdot 4)$ & $29 \cdot 2(0 \cdot 6)$ & $29 \cdot 3(0 \cdot 6)$ & $33 \cdot 5(0 \cdot 8)+5$ \\
\hline Crypt row count (no of cells) & $20.3(0.4)$ & $20.0(0 \cdot 1)$ & $20 \cdot 1(0 \cdot 3)$ & $21 \cdot 6(0.4)+5$ \\
\hline Crypt population (no of cells) & $596(16)$ & $582(11)$ & $588(16)$ & $723(26)+5$ \\
\hline \multicolumn{5}{|l|}{ Proximal colon } \\
\hline $\begin{array}{l}\text { Crypt depth }(\mu \mathrm{m}) \\
\text { Crypt column count (no of cells) }\end{array}$ & $\begin{array}{l}191(1 \cdot 0) \\
25 \cdot 6(1 \cdot 9)\end{array}$ & $\begin{array}{l}171(5) \\
22 \cdot 4(0 \cdot 7)\end{array}$ & $\begin{array}{l}173(6) \\
25 \cdot 1(0 \cdot 7)\end{array}$ & $\begin{array}{l}198(9)^{\star} \\
28 \cdot 5(0 \cdot 6) \dagger\end{array}$ \\
\hline
\end{tabular}

Values are expressed as means (SEM). Statistically significant difference from the vehicle group is indicated by ${ }^{\star}: p<0.05$ and $t: p<0.01$. Difference from the control group is indicated by $\ddagger: p<0.05$ and $s: p<0.01$. $n=6$ Animals per group except for the control group where $n=5$.

proportion to the total number of crypt cells and hence, the crypt growth fraction remained at approximately $60 \%$, Table III and Fig 3 (D).

The labelling distribution profiles in IGF-I treated rats also showed an increase in the overall crypt cell labelling index, which was virtually identical to that in $\mathrm{LR}^{3}$ IGF-I treated rats (Table III). In this group, the number of cells labelled with tritiated thymidine in basal and mid-crypt enterocytes (up to cell position 19) was also significantly increased (Table III), so that maximum thymidine labelling $(66 \cdot 7 \%)$ was reached within cell positions 5-16. Consequently, thymidine labelling in the lower and mid-crypt region in IGF-I treated animals was increased by $9 \%$ and $14 \%$ compared with vehicle treated or control rats, respectively. However, this failed to achieve statistical significance $(p<0.067)$ (Table III and Fig $3(C))$. In contrast with the LR ${ }^{3}$ IGF-I group, nuclear labelling declined more rapidly after cell position 16 (similar to the vehicle and control group) so that half maximum labelling was reached at cell position 20 in IGF-I treated rats, which was virtually identical to control values (Table III and Fig $3(\mathrm{C})$ ). As the total number of cells per crypt column was not changed in this group, the overall crypt growth fraction was maintained at $58 \%$ and comparable with the crypt growth fraction of the control groups (Table III). Thus, the mechanism by which IGF-I induced epithelial proliferation in this short-term administration protocol differed from that of the $\mathrm{LR}^{3} \mathrm{IGF}-\mathrm{I}$ group. Despite the considerable increase in the proliferative pool, short-term IGF-I administration did not increase the cellularity of the crypt. Increased crypt labelling was therefore achieved by increasing the proportion of proliferative cells in lower and mid-crypt positions as shown by the increase in maximal labelling rather than a recruitment of proliferative cells in higher cell positions, as seen in the LR $^{3}$ IGF-I group.

In the ileum, the overall crypt labelling index was lower than in the duodenum (Table III). This was reflected by lower thymidine labelling indices in the basal positions as well as a lower maximal labelling. On the other hand, the position of half maximum labelling was similar in the two intestinal regions (Table III). As for the duodenum, LR ${ }^{3}$ IGF-I treated animals showed an increased number of proliferative cells in higher cell positions (as shown by the upward shift in the $1 / 2$ maximum labelling), while IGF-I treatment seemed to increase the proportion of proliferative enterocytes in the mid-crypt cell positions (Table III), reaching a maximum thymidine labelling index of $60 \%$ compared with $54-57 \%$ in the control groups (Table III). This led to a non-significant $(p<0.08)$ increase in the crypt growth fraction in this group (Table III).

Finally, the mitogenic response of the colonic mucosa to IGF-I peptides was assessed in tissue segments from the proximal colon. Although, similar changes in wet tissue weight in LR $^{3} I G F-I$ treated rats were seen for the small and large intestine, thymidine labelling indices were not increased by IGF-I peptides (Table IV). Nevertheless, in LR $^{3}$ IGF-I treated rats, an average of 3.7 cells per crypt were labelled compared with 2.9 cells/crypt in vehicle or untreated control rats (Table IV). Although, statistical significance was not reached, it is possible that IGF-I peptides effects in the colon have been disguised by the inherent low proliferative activity of the colon. In this study, thymidine labelling indices were $11-13 \%$ for all groups with no statistical difference between treatment groups. The site at which histological samples for the colon were taken show a great deal of heterogeneity in crypt morphology. For example, the proximal

TABLE III Proliferative parameters in the duodenum and ileum of rats treated for three days with $2.5 \mathrm{mg} / \mathrm{kg} / \mathrm{day}$ of IGF-I or $L R^{3} I G F-I$ as compared with vehicle and untreated control rats

\begin{tabular}{|c|c|c|c|c|}
\hline \multirow[b]{2}{*}{ Proliferative parameter } & \multicolumn{4}{|c|}{ Treatment group } \\
\hline & Control & Vehicle & $I G F-I$ & $L R^{3} I G F-I$ \\
\hline \multicolumn{5}{|l|}{ Duodenum } \\
\hline Crypt labelling index (\%) & $29 \cdot 9(1.4)$ & $29 \cdot 1(0 \cdot 6)$ & $33.3(0.7)+5$ & $32 \cdot 7(0 \cdot 7)^{\star} \ddagger$ \\
\hline Maximal labelling (\%) & $58 \cdot 3(2 \cdot 9)$ & $61 \cdot 1(2 \cdot 2)$ & $66.7(1.9)$ & $65 \cdot 6(2 \cdot 0)$ \\
\hline Labelling up to cell position 19 (no of cells) & $7 \cdot 12(0 \cdot 38)$ & $7 \cdot 32(0 \cdot 09)$ & $8.45(0.07) \star S$ & $8 \cdot 34(0 \cdot 21) \star S$ \\
\hline $\begin{array}{l}\text { Cell position at } 1 / 2 \text { maximum labelling } \\
\text { Crypt growth fraction }(\%)\end{array}$ & $19 \cdot 6(0 \cdot 6)$ & $20 \cdot 1(0.5)$ & $20 \cdot 0(0 \cdot 9)$ & $24 \cdot 3(0 \cdot 8) \star \S$ \\
\hline \multicolumn{5}{|l|}{ Ileum } \\
\hline Crypt labelling index (\%) & $26 \cdot 2(0 \cdot 7)$ & $26 \cdot 0(0 \cdot 6)$ & $29 \cdot 2(0 \cdot 6)+5$ & $29 \cdot 4(0.6)+c$ \\
\hline Maximal labelling (\%) & $56 \cdot 7(3 \cdot 5)$ & $54 \cdot 6(1 \cdot 5)$ & $60 \cdot 0(2 \cdot 0)$ & $55 \cdot 2(2 \cdot 1)$ \\
\hline Labelling up to cell position 19 (no of cells) & $6 \cdot 88(0 \cdot 08)$ & $6.92(0.02)$ & $7 \cdot 33(0 \cdot 06) \dagger \ddagger$ & $7 \cdot 58(0 \cdot 13) \dagger \ddagger$ \\
\hline Cell position at $1 / 2$ maximum labelling & $19 \cdot 3(0 \cdot 6)$ & $18.7(0.9)$ & $20 \cdot 0(0 \cdot 3)$ & $23.3(0.7)+5$ \\
\hline Crypt growth fraction (\%) & $66 \cdot 3(2 \cdot 4)$ & $64 \cdot 2(1 \cdot 6)$ & $69 \cdot 5(0.5)$ & $69 \cdot 5(1 \cdot 6)$ \\
\hline
\end{tabular}

Values are expressed as means (SEM). Statistically significant difference from the vehicle group is indicated by ${ }^{\star}: \mathrm{p}<0.05$ and $t: p<0.01$. Differences from the untreated control rats are indicated by $\ddagger: p<0.05$ and $\$: p<0.01 . n=6$ Animals per group except for control group where $n=5$. The crypt labelling indices represent the proportion of tritiated thymidine labelled cells per crypt column and was calculated from 30 full length open crypt columns for each animal. Maximal labelling occurred in enterocytes in mid-crypt cell positions and was calculated from the top three thymidine labelled enterocytes within cell positions 5-16. 
Figure 3: Tritiated thymidine labelling distribution profiles in tissue sections from the duodenum in untreated control rats (A), rats treated with vehicle $(B)$ or rats treated with $2.5 \mathrm{mg} / \mathrm{kg} /$ day of either IGF-I (C) or $L R^{3} I G F-I(D)$. All values are represented as means $(n=5$, control and IGF-I). Sections from one animal in the IGF-I group were excluded because of very weak incorporation of the isotope. For all animals the mean tritiated labelling index (\%) was calculated from 30 full-length open crypts. Maximal labelling (\%) represents the average percentage of labelling in the top three labelled enterocytes within cell position 5-16. The crypt growth fraction was calculated for each animal individually as the cell position of half maximum labelling divided by the total number of cells per crypt column. The crypt growth fraction was calculated as the cell position of $1 / 2$ maximum labelling divided by the total number of cells per crypt column. (SEM) of 6 rats/group
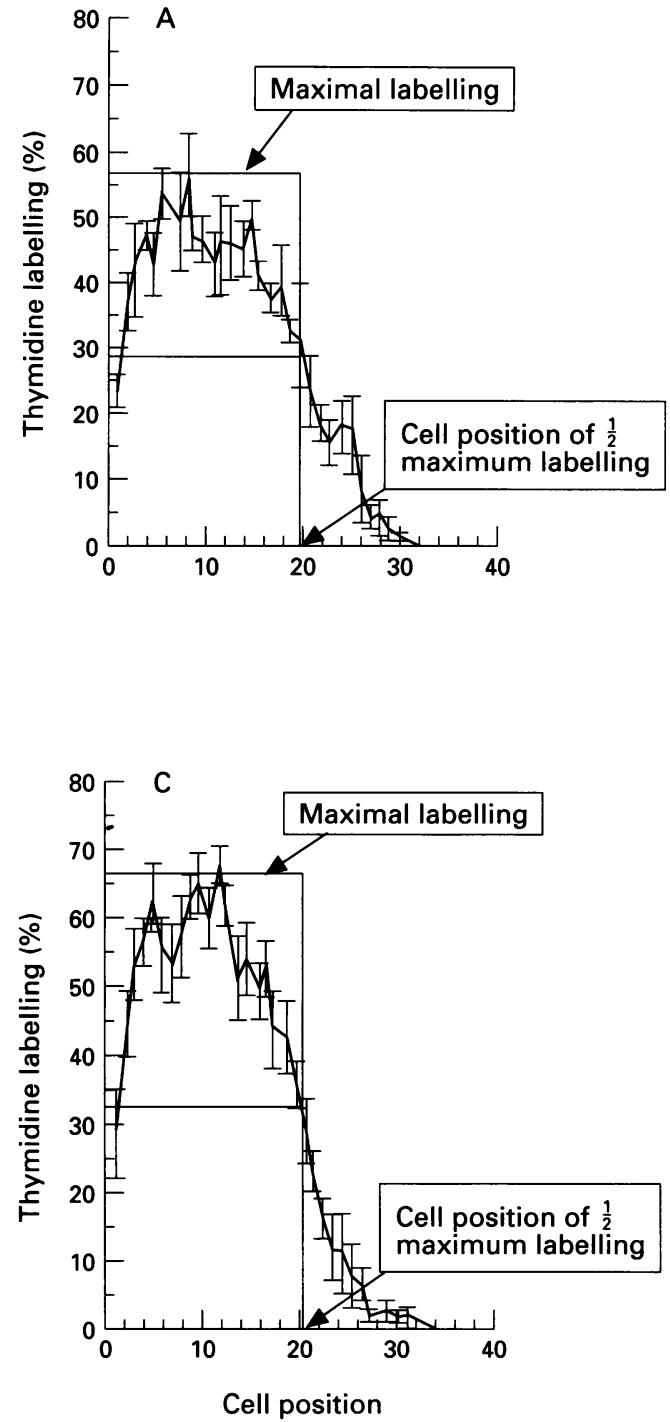

colon contains mucosal rugae and the crypts at the apex of mucosal folds are longer than the crypts at the base of the crypts. Consequently, the colonic crypt cell population could not be established because serial cut sections of longitudinal embedded material does not provide a uniform display of crypts suitable for circumferential crypt row counts in this region. Because of the low proliferative activity in the colon, labelling distribution curves were also not established for this region.

\section{Discussion}

We have previously shown that longterm infusion of IGF-I and in particular LR ${ }^{3}$ IGF-I

TABLE IV Proliferative parameters in the colon of rats treated for three days with $2.5 \mathrm{mg} / \mathrm{kg} /$ day of IGF-I or LR ${ }^{3} I G F-I$, compared with vehicle infused or untreated control rats

\begin{tabular}{|c|c|c|c|c|}
\hline \multirow[b]{2}{*}{ Proliferative parameter } & \multicolumn{4}{|c|}{ Treatment group } \\
\hline & Control & Vehicle & $I G F-I$ & $L R^{3} I G F-I$ \\
\hline \multicolumn{5}{|l|}{ Colon } \\
\hline $\begin{array}{l}\text { No of cells/crypt column } \\
\text { No of cells labelled/crypt column } \\
\text { Crypt labelling index (\%) }\end{array}$ & $\begin{array}{r}25 \cdot 6(1 \cdot 8) \\
2.9(0 \cdot 3) \\
11 \cdot 6(1 \cdot 6)\end{array}$ & $\begin{array}{r}22 \cdot 4(0 \cdot 7) \\
2 \cdot 9(0 \cdot 2) \\
13 \cdot 1(0 \cdot 6)\end{array}$ & $\begin{array}{r}25 \cdot 1(0 \cdot 7) \\
2 \cdot 9(0 \cdot 2) \\
11 \cdot 8(0 \cdot 8)\end{array}$ & $\begin{array}{l}28.5(0.6)^{\star} \dagger \\
3.7(0.2) \\
12.8(0.9)\end{array}$ \\
\hline
\end{tabular}

Values are expressed as means (SEM). Statistically significant difference from the vehicle group is indicated by ${ }^{\star}: p<0.05$. Differences from the untreated control rats are indicated by $t: p<0.05$ $n=6$ Animals per group except for IGF-I and control group where $n=5$. The crypt labelling indices represent the proportion of tritiated thymidine labelled cells per crypt column and wa calculated from 30 full length open colonic crypts of the proximal colon.
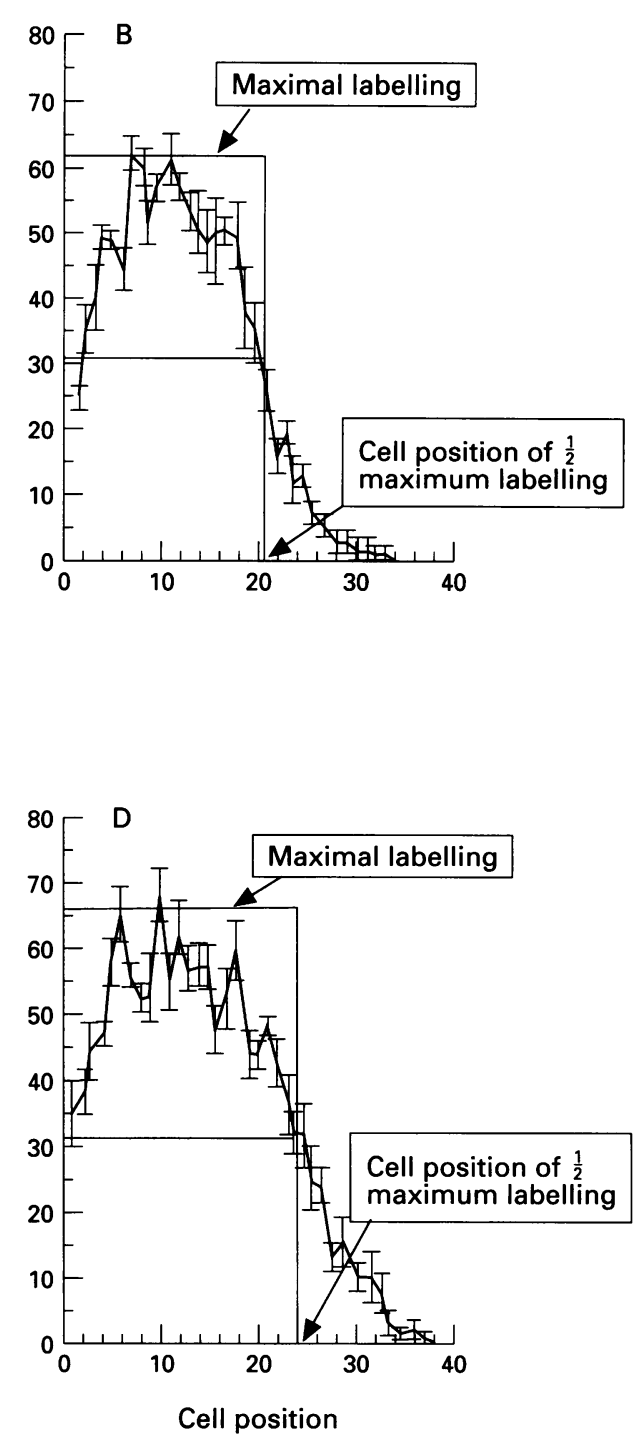

significantly enhanced mucosal growth in normal female rats. ${ }^{9}$ Treatment with either peptide resulted in a crypt hyperplasia with proportional increments in the percentage of cells labelled with PCNA, indicating that after 14 days of treatment with IGF-I peptides a new balance between crypt cell production and cell loss had been established. In this study, we have clearly shown that administration of IGF-I or LR ${ }^{3}$ IGF-I for three days to adult female rats elicits early proliferative events that lead to the massive increase in mucosal mass seen in the longterm infusion study. Moreover, comparing the total gut weight (wet tissue weight) of the rats treated for three days with $2.5 \mathrm{mg} / \mathrm{kg} /$ day of $L^{3} I G F-I$ with the total gut weight of rats treated for 14 days with the same peptide dose shows that $44 \%$ of the weight gain has occurred during the three day treatment period. In agreement with our findings, Olanrewaju et al, ${ }^{12}$ have shown that infusion of $10 \mathrm{nM}$ of hrIGF-I for three days into the ileal lumen of adult male Sprague-Dawley rats significantly increased mucosal mass (wet tissue weight) and the mucosal cellularity (as measured by DNA, RNA, and protein content of tissue homogenates). In addition, IGF-I administration effectively induced the growth related enzyme ornithine decarboxylase. ${ }^{12}$

The mitogenic properties of IGF-I to 
stimulate proliferation of intestinal epithelial cells has been well demonstrated in a number of in vitro studies. IGF-I is a potent mitogen for human fetal small intestinal cells. ${ }^{13}$ Administration of IGF-I to IEC-6 cells, a cell line derived from rat jejunal crypts, stimulate DNA and protein synthesis. Likewise, IGF-I stimulates cellular proliferation in RIE-1 cells, an epithelial cell line derived from rat small intestine. ${ }^{14}$ The tritiated thymidine uptake by canine fundic epithelial cells is also stimulated by IGF-I administration although EGF and insulin are also able to elicit a mitogenic response in these cells, much higher concentration of these growth factors are needed to achieve an equivalent effect. ${ }^{15}$ In this study, administration of IGF-I and LR ${ }^{3}$ IGF-I for a three day period stimulated the thymidine incorporation into crypt epithelial cells in vivo, supporting that in the adult rat, IGF-I peptides are important intestinal mitogens.

From the thymidine labelling distribution profiles in the control groups, it was evident that maximal thymidine incorporation was greatest in the mid-crypt region (cell position 5-16), which represents the zone of greatest cell production. As shown by Wright, ${ }^{16}$ this is the 'proliferative compartment proper' and the labelling index obtained in this region in our study compares well to the theoretical labelling index of $60 \%$. After treatment with IGF-I, an increase in the number of proliferative cells in lower and mid-crypt cells positions showed that more cells in this region of the crypt had entered the cell cycle, leading to the observed increase in the thymidine labelling index in this group. In addition, the maximum labelling was also increased, which shows that more cells in the proliferative compartment proper were cycling. The most probable mechanism by which such a rapid increase in proliferative activity may have been achieved is a reduction in the cell cycle in enterocytes in basal cell positions. Cell cycle times in basal cell positions, as measured by fraction labelled mitosis, stathmokinetic or continuous labelling methods, are prolonged compared with cell cycle times of enterocytes in the upper crypt region, ${ }^{17}$ so that a fractional decrease in the cell cycle time in basal positions would greatly increase the total proliferative pool within the crypt.

The most interesting finding of this study was the fact that although both IGF peptides significantly increased the thymidine incorporation into the crypt enterocytes, increased proliferative activity associated with an increase in the size of the crypt compartment was only seen in the LR ${ }^{3}$ IGF-I treated animals. Although we cannot exclude the possibility that the mechanism by which the two peptides induce proliferative events differs, it is highly likely that the proliferative responses seen in animals treated with $\mathrm{LR}^{3} \mathrm{IGF}-\mathrm{I}$ represent a more 'advanced' stage of intestinal proliferation compared with the IGF-I treated rats. This is supported by the fact that in rats treated for 14 days with either IGF-I or LR ${ }^{3}$ IGF-I a considerable increase in size of the crypt compartment was seen, for both groups. This suggests that although both peptides initiate increased thymidine incorporation after three days, in LR $^{3}$ IGF-I treated animals this has been already translated into an increase in crypt size, which in IGF-I treated animals occurs some time later. Thus, the proliferative effect seen in the rats infused with IGF-I should be detectable after administration of LR $^{3}$ IGF-I for only one or two days.

Another point of interest was the finding that administration of $\mathrm{LR}^{3} \mathrm{IGF}-\mathrm{I}$ resulted in a greater proportion of cycling cells in upper crypt cell positions, showing that migrating enterocytes had retained their proliferative capacities and had not entered the maturation compartment of the crypt. Moreover, it seems that in LR ${ }^{3}$ IGF-I treated animals the proliferative response was approaching the new steady state equilibrium between cell production and cell loss that was seen in the rats treated for 14 days with IGF-I peptides. This may have been achieved by a change in enterocyte transit time.

The accelerated proliferative effects of LR $^{3}$ IGF-I may have been the result of several interacting factors. $\mathrm{LR}^{3} \mathrm{IGF}-\mathrm{I}$ has a severalfold lower affinity towards IGFBP-3, IGFBP-4, total rat plasma, and L6 myoblast binding proteins. ${ }^{18}$ Despite the reduced affinity to binding proteins, however, LR ${ }^{3}$ IGF-I has shown a substantially greater bioactivity than IGF-I in several functional assays associated with growth in L6 myoblasts and H35 hepatoma cells. ${ }^{10}$ This increased potency is seen despite the fact that the analogue binds with approximately fourfold lower affinity to the type 1 receptor. ${ }^{10}$ It is possible that infusion of $2.5 \mathrm{mg} / \mathrm{kg} /$ day of LR $^{3} I G F-I$ may have increased the free IGF pool in plasma to a greater extent than infusion of the IGF-I. This would lead to a greater amount of IGF molecules free to interact with their respective receptors stimulating intestinal mitogenesis through signal transduction pathways, thus in $\mathrm{LR}^{3} \mathrm{IGF}-\mathrm{I}$ treated animals proliferative events may have induced more rapidly than in IGF-I treated rats.

Another contributing factor is the fact that LR $^{3}$ IGF-I is also cleared more rapidly from the circulation. ${ }^{19}$ For example, the metabolic clearance rate for $\mathrm{LR}^{3} \mathrm{IGF}-\mathrm{I}$ is approximately 11-fold higher than for IGF-I in adult female Sprague-Dawley rats. ${ }^{19}$ In addition, location of radiolabelled IGF-I or $\mathrm{LR}^{3} \mathrm{IGF}-\mathrm{I}$ in visceral organs and tissues differs between the two peptides. ${ }^{19}$ The increased potency seen with LR ${ }^{3}$ IGF-I may also result from reduced interaction of the analogue with locally produced binding proteins. Most probably, a combination of complex interactions between the IGF-I ligand, endogenous IGF binding proteins present in the serum and tissues, clearance rates, and tissue distribution and the availability of the analogue to the IGF receptor determined the rapid mitogenic response.

Direct action of IGF-I peptides on the gastrointestinal tract is supported by the localisation of IGF receptors along the entire length of the rat intestine. ${ }^{20-24}$ Similarly, a single class of high affinity IGF-I receptors have 
been localised to the muscular and mucosal layer of the gastrointestinal tract in rabbits ${ }^{25}$ and both type 1 and type 2 receptors are present in the porcine small intestine. ${ }^{4}$ As shown by membrane receptor binding studies in the rat, ${ }^{125} \mathrm{I}-\mathrm{IGF}-\mathrm{I}$ binding to IGF-I receptors was fourfold higher in proliferative crypt cells than in villus cells and IGF-I receptor densities are greater in the lamia propria than in the surface epithelium in adult rat intestine. ${ }^{23}$ This shows that the mitogenic properties of IGF-I peptides are more probably mediated by a direct interaction of the IGF-I ligand with the cell surface receptor. Indirect action of IGF peptides on gastrointestinal tissues can, however, not be dismissed and additional and synergistic interactions of IGF-I and other growth factors have been reported. ${ }^{13} 26$

In agreement with previous studies, 89 the proximal small intestine was identified as the most responsive region despite the fact that in the rat, binding of ${ }^{125} \mathrm{I}-\mathrm{IGF}-\mathrm{I}$ is lower in cryostat sections of the proximal small intestine compared with the distal small intestine or the colon. ${ }^{20} 23$ In this study, administration of $\mathrm{LR}^{3} \mathrm{IGF}-\mathrm{I}$ increased the wet tissue weight of the colon to a similar extent to that of the small intestine, yet an increase in thymidine labelling was not seen. The proliferative effect of IGF-I peptides may have been somewhat disguised by the inherent low proliferative activity of the colon. In the colon, variation in crypt morphology, in particular in the proximal colon, lead to a great deal of heterogeneity in morphometric and cell kinetic parameters. For example, in the rat, colonic crypts become longer and more slender with distance away from the ileocaecal junction. Furthermore, mucosal rugae are prominent in the proximal colon but not in the distal colon and crypts at the apex of the mucosal folds are longer than the crypts at the base of the folds (reviewed by Wright and Alison, ref 16). Thus, to estimate more accurately the proliferative response of IGF-I peptides on the colonic mucosa, direct measurements of cell cycle time or the crypt cell production rates, or both, need to be taken.

In summary, this study has shown that administration of $\mathrm{LR}^{3} \mathrm{IGF}-\mathrm{I}$ for only three days strongly stimulated intestinal proliferation in normal adult rats. LR $^{3}$ IGF-I but not IGF-I increased the wet tissue weight of intestinal components independent of food intake. In this group, the crypt length and crypt cell number were increased in the duodenum and ileum. Although thymidine labelling indices were increased for both peptides, no change in the crypt length and crypt cell population was seen for IGF-I treated rats, suggesting that $\mathrm{LR}^{3} \mathrm{IGF}-\mathrm{I}$ is not only more potent in stimulating intestinal proliferation but induces mitogenesis more rapidly.

1 Lund PK. Insulin-like growth factors. In. Walsh $\mathrm{JH}$ Dockray GH, eds. Gut peptides: biochemistry and physiolDockray GH, eds. Gut peptides: biochemistry
2 D'Ercole AJ, Hill DJ, Strain AJ, Underwood LE. Tissue and plasma somatomedin-C/insulin-like growth factor I concentrations in the human foetus during the first half of gestation. Pediatr Res 1986; 20: 253-5.

3 Romanus JA, Yang YWH, Adams SO, Sofair AN, Tseng LYH, Nissley SP, et al. Synthesis of insulin-like growth factor II (IGF-II) in foetal rat tissues: translation of IGFII ribonucleic acid and processing of pre-pro-IGF-II Endocrinology 1988; 122: 709-16.

4 Schober DA, Simmen FA, Hadsell DL, Baumrucker CR. Perinatal expression of type 1 IGF receptors in porcine small intestine. Endocrinology 1990; 126: 1125-32.

5 Chaurasia OP, Marcuard SP, Seidel ER. Insulin-like growth factor $I$ in human gastrointestinal exocrine secretions. Regul Pept 1994; 50: 113-9.

6 Lemmey AB, Martin AA, Read LC, Tomas FM, Owens PC, Ballard FJ. IGF-I and the truncated analogue des(13)IGF-I enhance growth in rats after gut resection. $A m \mathcal{F}$ Physiol 1991; 260: E213-9.

7 Vanderhoof JA, McCusker RH, Clark R, Mohammadpour $\mathrm{H}$, Blackwood DJ, Harty RF, et al. Truncated and native insulin-like growth factor-I enhance mucosal adaptation after jejunoileal resection. Gastroenterology 1992; 102: 1949-56.

8 Read LC, Tomas FM, Howarth GS, Martin AA, Edson KJ, Gillespie CM, et al. Insulin-like growth factor-I and its $\mathrm{N}$-terminal modified analogues induced marked gut growth in dexamethasone treated rats. $\mathcal{F}$ Endocrinol 1992;

Steeb C-B, Trahair JF, Tomas FM, Read LC. Prolonged administration of IGF peptides enhances growth of gasadministration of IGF peptides enhances growth of gastrointestinal $1090-8$.

10 Francis GL, Ross M, Ballard FJ, Milner SJ, Senn C, McNeil KA, et al. Novel recombinant fusion-protein analogues of insulin-like growth factor I (IGF-I) indicate the relative importance of IGF-binding protein and receptor binding for enhanced biological potency. $\mathfrak{f} \mathrm{Mol}$ Endocrinol 1992; 8: 213-23.

11 Sokal RR, Rohlf FJ. In: Sokal RR, Rohlf FJ, eds. Introduction to Biostatistics. New York: WH Freeman, 1987: 270-80.

2 Olanrewaju $\mathrm{H}$, Patel I Seidel ER. Trophic action of local intraileal infusion of insulin-like orowth factor-I: intraileal infusion of insulin-like growth factor-1.

polyamine dependence. Am f Physiol 1992; 263: E282-6. and insulin-like growth factors enhance the proliferative affects of growth factors. Gastroenterology 1990; 98: effects

14 Corps AN, Brown KD. Stimulation of intestinal cell proliferation in culture by growth factors in human and ruminant mammary secretions. $\mathcal{f}$ Endocrinol 1987; 113: 258-90.

15 Chen MC, Lee AT, Soll AH. Mitogenic response of canine fundic epithelial cells in short-term culture to transforming growth factor and insulin-like growth factor I. $\mathcal{F} \mathrm{Cl}$ Invest 1989; 87: 1716-23.

16 Wright NA. The organization of epithelial cell populations. In: Appleton DR, Sunter JP, Watson AJ, eds. Cell proliferation in the gastrointestinal tract. Bath: Pitman Press, 1980: 3-21.

17 Al-Dewachi HS, Wright NA, Appleton DR, Watson AJ. The cell cycle time in rat jejunal crypt. Cell Tissue Kine The cell cycle time

18 Ballard FJ, Walton PE, Bastian S, Tomas FM, Wallace JC, Francis GL. Effects of interactions between IGFBPs and IGFs on the plasma clearance and in vivo biological activities of IGFs and IGF analogs. Growth Regul 1993; 3: 40-4.

19 Bastian SEP, Walton PE, Wallace JC, Ballard FJ. Plasma clearance and tissue distribution of labelled insulin-like growth factor-I (IGF-I) and LR3IGF-I in pregnant rats. $\mathcal{F}$ Endocrinol 1993; 138: 327-36.

20 Laburthe M, Royer-Fessard Ch, Gammeltoft S. Receptors for insulin-like growth factors I and II in rat gastrointestinal epithelium. Am F Physiol 1988; 254: G457-62.

21 Ryan J, Costigan DC. Determination of the histological distribution of insulin-like growth factor I receptors in the distribution of insulin-like growth

22 Young GP, Taranto TM, Jonas HA, Cox AJ, Hogg A, Werther GA. Insulin-like growth factor and the developing and mature rat small intestine: receptors and biological actions. Digestion 1990; 46: 240-52.

23 Heinz-Erian P, Kessler U, Funk B, Gais G, Kiess W. Identification and in situ localisation of the insulin-like growth factor-II/mannose-6-phosphate (IGF-II/M6P) receptor in the rat gastrointestinal tract: comparison with the IGF-I receptor. $\mathcal{F}$ Endocrinol 1991; 129: 1769-77.

24 MacDonald RS, Park JHY, Thornton WH. Insulin, IGF-I and IGF-II receptors in rat small intestine following massive small bowel resection: analysis by binding flowcytometry and immunohistochemistry. Dig Dis Sci 1993; 38: 1658-69.

25 Termanini BR, Nardi V, Finan TM, Parikh I, Korman LY. Insulin-like growth factor I receptors in the rabbit gasInsulin-like growth factor I receptors in the rabbit
trointestinal tract. Gastroenterology 1990; 99: 51-60.

26 Lynch SE, Colvin RB, Antoniades HN. Growth factors in wound healing: single and synergistic effects of partial thickne 